\title{
Sitagliptin as combination therapy in the treatment of type 2 diabetes mellitus
}

This article was published in the following Dove Press journal:

Diabetes, Metabolic Syndrome and Obesity:Targets and Therapy

13 May 2009

Number of times this article has been viewed

\author{
Shannon A Miller' \\ Erin L St Onge ${ }^{2}$ \\ J Roger Accardi ${ }^{3}$ \\ 'Pharmacotherapy Faculty, Florida \\ Hospital East Family Practice \\ Residency, Orlando, Florida, USA; \\ ${ }^{2}$ University of Florida College of \\ Pharmacy, Orlando Campus, Florida, \\ USA; ${ }^{3}$ Accardi Clinical Pharmacy, \\ Orange City, Florida, USA
}

\begin{abstract}
The American Diabetes Association and The European Association for the Study of Diabetes recommend metformin as the initial agent of choice in the treatment of type 2 diabetes mellitus. Unfortunately, most patients require multiple medications to obtain glycemic control. One of the newest additions to the antidiabetic armamentarium is the class of drugs known as dipeptidyl-peptidase IV (DPP-IV) inhibitors. This novel approach focuses on harnessing the beneficial effects of GLP-1, an incretin hormone released from the gut postprandially. The first DPP-IV inhibitor approved in the United States was sitagliptin. It has been studied in both monotherapy and combination therapy. Combination studies with metformin realize a hemoglobin A1c reduction of $0.65 \%-1.1 \%$. The combination of the two has a modest positive effect on body weight with the convenience of an oral route of administration. It has also been shown to be highly tolerable, efficacious and with little risk of hypoglycemia. This review will focus on combination therapy with sitagliptin with emphasis on combination with metformin.
\end{abstract}

Keywords: DPP-IV inhibitor, sitagliptin, metformin, type 2 diabetes, incretins

\section{Introduction}

According to current estimates, type 2 diabetes mellitus (T2DM) affects approximately 21 million Americans. ${ }^{1}$ Insulin resistance, the primary defect present in T2DM, is mainly due to genetic and lifestyle factors. Current treatment strategies focus on lifestyle changes, reducing hyperglycemia, and improving insulin sensitivity. Weight loss and oral medications improve insulin sensitivity and lower blood glucose by decreasing insulin resistance. Other agents including insulin secretagogues, biguanides, insulin analogs, and dipeptidyl peptidase (DPP-IV) inhibitors also reduce blood glucose, through diverse mechanisms. Despite this wide array of treatment options, most patients remain above goal.

Sitagliptin, a DPP-IV inhibitor, helps the body take advantage of the incretin hormone glucagon-like peptide (GLP-1). GLP-1 is released from the gastrointestinal tract in response to a meal. When blood glucose is elevated, GLP-1 stimulates insulin secretion. In addition, GLP-1 reduces glucagon secretion, slows gastric emptying, and appears to regulate the growth of insulin producing $\beta$-cells (Figure 1 ). ${ }^{2}$ GLP-1 is rapidly inactivated by the DPP-IV enzyme. ${ }^{3}$ By inhibiting DPP-IV, the positive effects of GLP-1 are prolonged. This article reviews publications and abstracts involving combination therapy with sitagliptin. These trials should provide greater insight into sitagliptin's role in combination therapy.

\section{Pharmacology}

Experts have identified multiple signals leading from the gastrointestinal tract to the pancreas. ${ }^{4}$ An experiment first described in the 1960 s compared the metabolic 


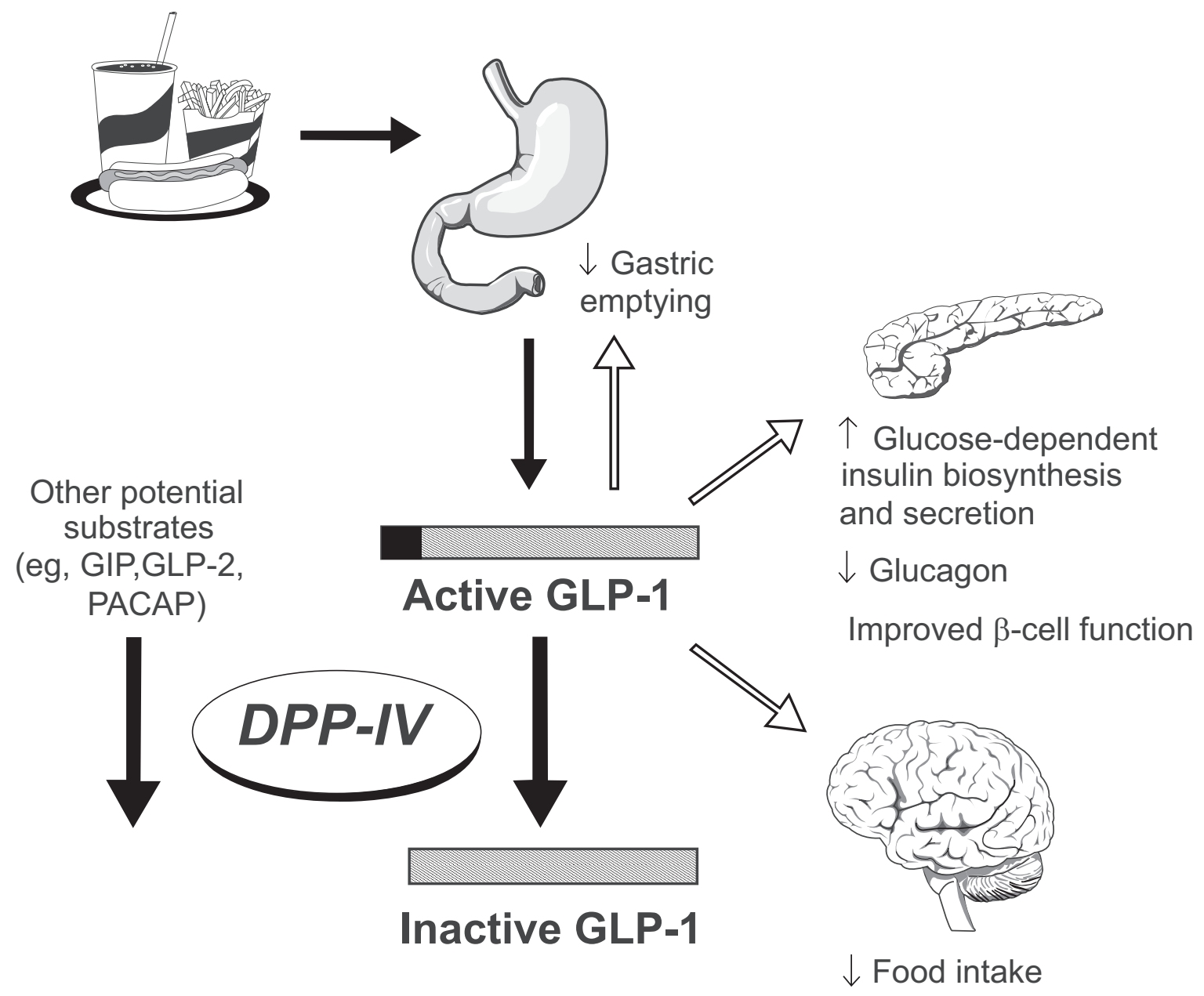

Figure I The role of glucagon-like peptide (GLP-I) in glucose homeostasis. Reprinted with permission from Weber A. Dipeptidyl peptidase IV inhibitors for the treatment of diabetes. J Med Chem. 2004;47:4I35-4I4I. ${ }^{2}$ Copyright (C) American Chemical Society.

response to a glucose load delivered intravenously versus orally. Levels of serum glucose appeared similar; however the plasma insulin response evoked from the oral glucose load was far greater. In other words, the intravenous glucose load provided a suboptimal insulin response when compared to an oral glucose load. This has been termed the incretin effect; the majority of its effect modulated by the incretin hormones GLP-1 and glucose-dependent insulinotropic peptide (GIP).

An incretin is a hormone that is released from the gut in response to nutrients (mainly carbohydrates), stimulates insulin release in response to a meal, and causes insulin release in a glucose dependent manner. ${ }^{4}$ The gastrointestinal hormone GLP-1 is quickly inactivated by the DPP-IV enzyme. DPP-IV is found in the kidneys, intestines, and bone marrow with lower concentrations in the liver, pancreas, placenta, thymus, spleen, epithelial cells, vascular endothelium, and lymphoid and myeloid cells., ${ }^{2,5}$
Patients with T2DM have been shown to have reduced concentrations of intact GLP-1. Vilsboll et al conducted a study involving 12 subjects with T2DM and 12 healthy controls. ${ }^{6}$ Blood samples were collected at $15,30,45$, $60,75,90,120,150$, and 180 minutes postprandially to determine intact GLP-1 concentrations. GLP-1 concentrations were lower in patients with diabetes 75 , 90 , and 120 minutes after meal ingestion $(\mathrm{p}=0.056$, 0.017 , and 0.017 , respectively). In addition, insulin and C-peptide concentrations were decreased during these same time periods, indicating an abnormal insulin response. The investigators concluded that in the absence of normal concentrations of intact GLP-1, the insulin response in patients with T2DM is blunted.

\section{Kinetics}

The oral bioavailability of sitagliptin is $87 \%$ with a terminal half-life of 10 to 12 hours. Median time to maximum 
concentration (Tmax) is 1 to 6 hours and varies across the dosing range; sitagliptin is excreted primarily by the kidneys. ${ }^{7,8}$ Neither the absorption, Tmax, nor the half-life are significantly altered when sitagliptin is administered with food. Although sitagliptin is a minor substrate for the CYP450 system, it is not an inhibitor or inducer of this system. ${ }^{7}$ The apparent volume of distribution is $198 \mathrm{~L}$ and sitagliptin has been reported to be $38 \%$ bound to plasma proteins. $^{7}$

\section{Clinical trials}

Sitagliptin has been studied with metformin, glipizide, glimepiride and pioglitazone (Table 1). One of the first studies to address sitagliptin as add-on therapy to metformin in patients with inadequate glycemic control was conducted by Brazg and colleagues. ${ }^{9}$ In this doubleblind, randomized, placebo-controlled, cross-over study, 28 patients (baseline $\mathrm{HgbA} 1 \mathrm{c}$ [A $1 \mathrm{c}$ ] ranging from $6.5 \%$ to $9 \%$ ) received sitagliptin $50 \mathrm{mg}$ twice daily or placebo for 4 weeks followed by the opposite treatment for an additional 4 weeks. The primary endpoint analyzed was 24-hour weighted mean glucose (WMG); secondary endpoints included fasting plasma glucose (FPG) and fructosamine. There was a significant least-squares mean reduction in WMG, FPG and fructosamine $(32.8 \mathrm{mg} / \mathrm{dL}, 20.3 \mathrm{mg} / \mathrm{dL}$, and $33.7 \mathrm{mmol} / \mathrm{L}$, respectively). The addition of sitagliptin did not lead to additional adverse events compared to metformin monotherapy. This short term study highlighted the efficacy and tolerability of combination therapy with metformin and sitagliptin.

A 24-week study conducted by Goldstein, et al assessed the effect of adding sitagliptin and metformin in 1091 patients inadequately controlled on diet and exercise alone. ${ }^{10}$ This double-blind, placebo-controlled, parallel-group study randomized patients to one of six treatment groups: sitagliptin $100 \mathrm{mg}+$ metformin $1000 \mathrm{mg}$, sitagliptin $100 \mathrm{mg}+$ metformin $2000 \mathrm{mg}$, metformin $1000 \mathrm{mg}$, metformin $2000 \mathrm{mg}$, sitagliptin $100 \mathrm{mg}$, or placebo. The mean baseline A1c was $8.8 \%$. The placebo subtracted changes in A1c after 24 weeks of treatment were $2.07 \%, 1.57 \%, 1.3 \%, 0.99 \%$, and $0.83 \%$ for the sitagliptin $100 \mathrm{mg}+$ metformin $1000 \mathrm{mg}$, sitagliptin $100 \mathrm{mg}+$ metformin $2000 \mathrm{mg}$, metformin $1000 \mathrm{mg}$, metformin $2000 \mathrm{mg}$, and sitagliptin $100 \mathrm{mg}$ groups, respectively ( $\mathrm{p}<0.001$ for all comparisons versus placebo). The incidence of hypoglycemia reported was low $(0.5 \%$ to $2.2 \%$ ) and similar to placebo $(0.6 \%)$; sitagliptin did not appear to increase gastrointestinal adverse events associated with metformin use. The authors concluded combination therapy with metformin and sitagliptin provides additive glycemic benefit and is generally well tolerated.

Charbonnel et al conducted a 24-week randomized, double-blind, parallel-group study in 701 patients. ${ }^{11}$ This study assessed the safety and efficacy of adding sitagliptin to ongoing metformin therapy ( $\geq 1500 \mathrm{mg} /$ day) in patients with a mean A1c of $8.0 \%$. Patients were randomized to receive sitagliptin $100 \mathrm{mg}$ daily or placebo. At study end, sitagliptin treatment produced a significant reduction in A1c $(0.65 \%, p<0.001)$, and FPG $(25.4 \mathrm{mg} / \mathrm{dL}, \mathrm{p}<0.001)$. No increase in the incidence of gastrointestinal events was noted and hypoglycemia rates between groups were similar. Nasopharyngitis, urinary tract infection, arthralgia, back pain and cough were all experienced at a higher incidence in the sitagliptin group compared to placebo. Body weight remained neutral. The authors concluded that sitagliptin $100 \mathrm{mg}$ once daily was well tolerated and provided sustained improvements in A1c and FPG in patients inadequately controlled on metformin monotherapy. A 30-week extension was then conducted. ${ }^{12}$ Patients initially treated with sitagliptin remained on the drug, while patients taking placebo were switched to glipizde $5 \mathrm{mg}$ daily (titrated to a maximum dose of $15 \mathrm{mg}$ /day). Of the original 701 patients randomized, 544 patients continued with this portion of the study (sitagliptin $n=387$, glipizide $n=157$ ). For patients already on sitagliptin, the A1c did not change significantly from week 24 to week $52(-0.07 \%)$. The change in A1c from baseline was $-0.7 \%$ (p-value not reported) in the sitagliptin arm and $-0.9 \%$ (p-value not reported) in the glipizide arm. Hypoglycemia was reported more in the glipizide group compared to sitagliptin ( $16 \%$ versus $<1 \%$, respectively). The sitagliptin group experienced a weight reduction of $0.9 \mathrm{~kg}$ from baseline; conversely, patients in the glipizide arm recorded a weight gain of $1.5 \mathrm{~kg}$.

In a long term trial, Nauck and colleagues conducted a non-inferiority study to compare the effects of adding sitagliptin or glipizide to patients uncontrolled on metformin monotherapy (mean baseline A1c 7.5\%). ${ }^{13}$ Patients were randomized to receive sitagliptin $(\mathrm{n}=588) 100 \mathrm{mg}$ daily or glipizide $(\mathrm{n}=584) 5 \mathrm{mg}$ daily (titrated to a maximum of $20 \mathrm{mg}$ daily) for 52 weeks. The primary endpoint was defined as the change in A1c from baseline. A1c changes from baseline were $-0.67 \%$ for both groups, confirming noninferiority of sitagliptin. Fasting plasma glucose decreased from baseline in the sitagliptin group $(10.0 \mathrm{mg} / \mathrm{dL}$, p-value not reported) as well as the glipizide group $(7.5 \mathrm{mg} / \mathrm{dL}$, $\mathrm{p}$-value not reported). More patients in the glipizide group experienced hypoglycemia $(32 \%, \mathrm{p}<0.001)$ compared to 


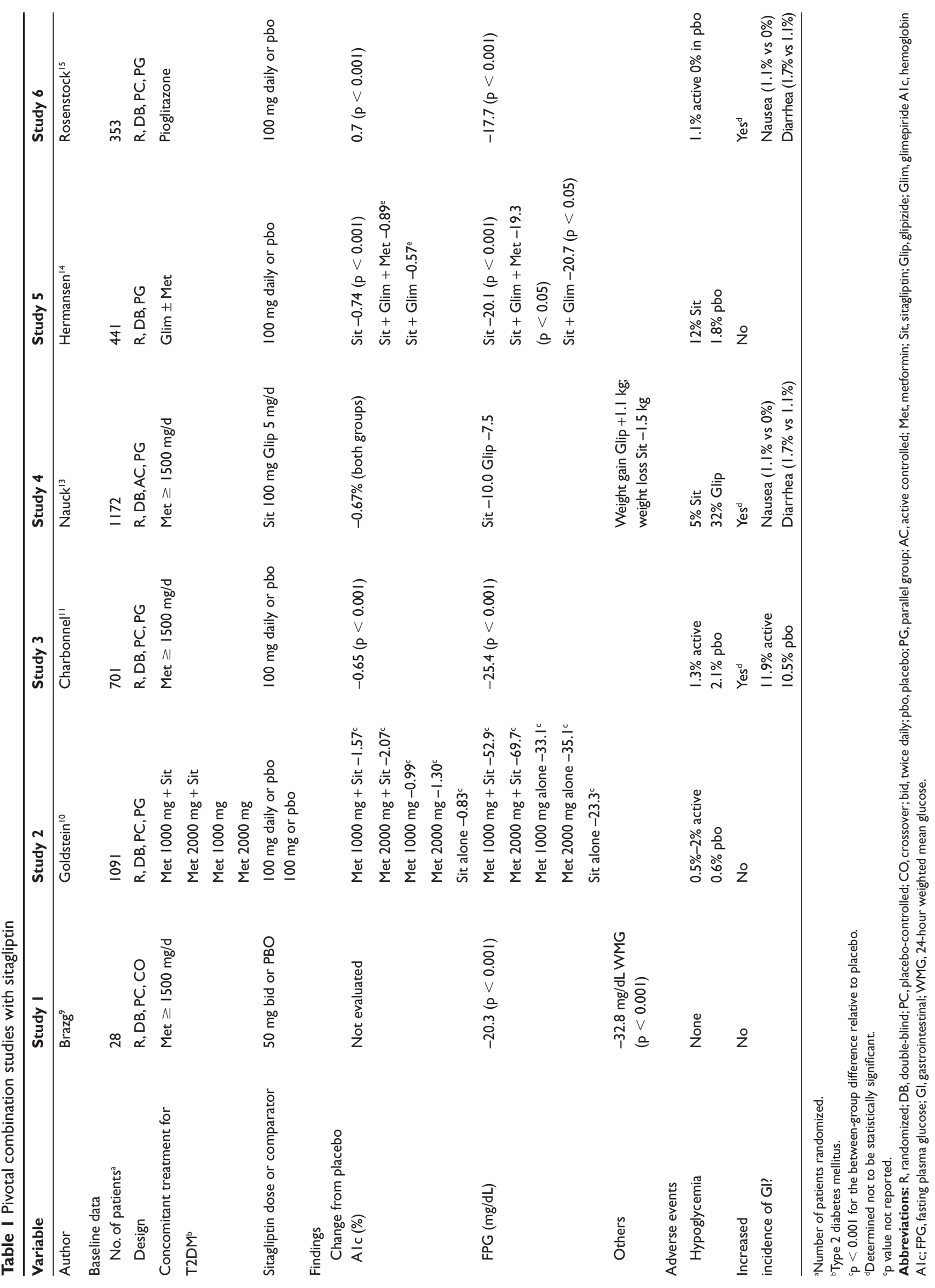


sitagliptin $(5 \%, \mathrm{p}<0.001)$. Body weight was reduced with sitagliptin $(1.5 \mathrm{~kg}, \mathrm{p}<0.001)$, compared with weight gain in the glipizide arm $(1.1 \mathrm{~kg}, \mathrm{p}<0.001)$. The authors concluded that sitagliptin is comparable to glipizide in glycemic control but free from significant hypoglycemia and weight gain.

The safety and efficacy of sitagliptin addition was studied in a 24-week, randomized, double-blind trial in patients inadequately controlled on glimepride with or without metformin. ${ }^{14}$ Patients were randomized to receive the addition of sitagliptin $100 \mathrm{mg}$ daily or placebo (212 on glimepiride, 229 on glimepiride and metformin). After 24 weeks, sitagliptin reduced the A $1 \mathrm{c}$ by $0.74 \%(\mathrm{p}<0.001)$ in the overall randomized cohort of patients. In the subset of patients receiving metformin and glimepiride, the largest A1c reduction was noted $(0.89 \%$, p-value not reported), compared to the subset of patients on glimepiride alone $(-0.57 \%$, p-value not reported $)$. Fasting and postprandial blood glucose also improved with the addition of sitagliptin. Hypoglycemia was higher in the sitagliptin group compared to placebo $(12 \%$ vs $2 \%$, p $<0.001)$; however, no episodes required medical attention. At study end, the placebo-adjusted body weight was increased in the sitagliptin arm $(1.1 \mathrm{~kg}, \mathrm{p}<0.001)$.

The combination of sitagliptin and pioglitazone was explored in a 24-week, double-blind, placebo-controlled, parallel-group study. ${ }^{15}$ In this study, 353 patients on pioglitazone monotherapy ( 30 or $45 \mathrm{mg} /$ daily) were randomized to receive either the addition of sitagliptin $100 \mathrm{mg}$ daily or placebo. The primary efficacy end point was change in A1c from baseline to study end. Fasting plasma glucose was a secondary end point. The addition of sitagliptin significantly reduced A1c with a between-treatment difference of $0.7 \%$ ( $p<0.001)$. Fasting plasma glucose also decreased by $17.7 \mathrm{mg} / \mathrm{dL}(\mathrm{p}<0.001)$. The proportion of patients able to reach an A1c of $<7 \%$ was $45.4 \%$ in the sitagliptin group versus $23.0 \%$ in the placebo group. The sitagliptin plus pioglitazone group experienced a higher incidence of gastrointestinal adverse effects than placebo (13.7\% vs $6.2 \%$, respectively). No significant difference in hypoglycemia was observed. Both groups experienced one episode of edema; no reports of congestive heart failure were observed. The authors concluded that the combination of sitagliptin plus pioglitazone is well tolerated and significantly improves glycemic control.

\section{Clinical trial limitations}

Findings discussed in the above trials are limited to specific populations enrolled in each trial. To date, most of the clinical trials involving sitagliptin combination therapy are limited to metformin. Additional studies involving combination therapy with sitagliptin and other antihyperglycemic agents are needed in order to make recommendations regarding optimal combination therapy. Also, the efficacy and safety of sitagliptin combination therapy has not been evaluated beyond one year; future trials of longer duration will be needed to define its role. Given sitagliptin's potential to affect disease progression, effects on microvascular and macrovascular outcomes should also be explored.

\section{Adverse events}

The most common adverse events associated with sitagliptin include nasopharyngitis, upper respiratory tract infection, and headache. Other adverse events reported with sitagliptin include abdominal pain, nausea, diarrhea, and vomiting; however, the incidence of these adverse events are similar to placebo. ${ }^{7}$ In clinical trials sitagliptin has not been associated with any significant changes in complete blood counts, transaminase and serum creatinine levels, vital signs, or electrocardiogram. ${ }^{7}$ It is important to note, however, that hypersensitivity reactions such as anaphylaxis, angioedema, and Stevens-Johnson syndrome have been reported during post-marketing surveillance. ${ }^{16}$

Hypoglycemia, an adverse event that plagues several of the other available treatments for T2DM, is not significant with sitagliptin therapy. In fact, a pooled analysis of four studies showed that the incidence of hypoglycemia was $1.2 \%$, $0.9 \%$, and $0.9 \%$ with sitagliptin $100 \mathrm{mg}$, sitagliptin $200 \mathrm{mg}$, and placebo, respectively. ${ }^{8}$

Weight gain is another adverse event of concern to practitioners treating T2DM. Treatment with sitagliptin has shown variable results. Monotherapy studies with sitagliptin showed a small reduction in weight; however, a greater reduction was experienced by the placebo groups. When combined with metformin or pioglitazone, weight changes were similar relative to placebo. Sitagliptin in combination with sulfonylureas led to a significant weight increase when compared to the placebo groups. ${ }^{8}$

\section{Drug interactions}

Sitagliptin appears to be well tolerated with a marginal drug interaction profile. It is a minor substrate of the CYP450 system, but is not an inhibitor or inducer of any of the isoenzymes. ${ }^{7}$ Sitagliptin is not extensively bound to plasma proteins. ${ }^{7}$ Subsequently, the probability of sitagliptin being involved in clinically meaningful drug-drug interactions mediated by protein plasma binding is quite low. The combination of sitagliptin and metformin when co-admin- 
istered does not extensively alter the pharmacokinetics of either agent. ${ }^{17}$ Sitagliptin has been found to increase the area under the curve (AUC) and plasma concentration of digoxin; however, no dosage adjustment is required. ${ }^{18}$ When administered with cyclosporine, drug exposure and peak concentrations of sitagliptin are increased; therefore, a dose reduction of sitagliptin may be warranted and careful monitoring should be conducted. ${ }^{18}$

\section{Dosing and administration}

The recommended starting dose for sitagliptin is $100 \mathrm{mg}$ daily. Sitagliptin can be given without regards to meals. The dose should be reduced to $50 \mathrm{mg}$ daily with a creatinine clearance $(\mathrm{CrCl})$ of 30 to $50 \mathrm{~mL} / \mathrm{min}$ and to $25 \mathrm{mg}$ daily with $\mathrm{CrCl}$ less than $30 \mathrm{~mL} / \mathrm{min}^{7}{ }^{7}$ Patients with T2DM less than 18 years of age should not receive sitagliptin. Sitagliptin is considered pregnancy category B; it is unknown whether sitagliptin is excreted into breast milk. A dose adjustment is not required in geriatric patients; however, caution should be exercised when using sitagliptin in patients who are over 75 years of age. ${ }^{18}$

Numerous clinical trials with the combination of sitagliptin and metformin have led to the development of Janumet $^{\mathrm{TM}}$ (Merck and Co., Inc.), the only commercially available combination product with the aforementioned agents. ${ }^{19}$ Dosing with sitagliptin and metformin should be individualized as dictated by efficacy and tolerability. The maximum recommended daily dose for metformin is $2550 \mathrm{mg}$ in divided doses; however, increasing the dose over $2000 \mathrm{mg}$ provides marginal benefit. ${ }^{20}$ The maximum recommended dose of sitagliptin is $100 \mathrm{mg}$ daily in a single or divided dose. ${ }^{21}$ Janumet $^{\mathrm{TM}}$ should be started at the initial dose of 50/500 twice daily for patients with type 2 diabetes not adequately controlled on diet and exercise alone. Dosing may be titrated to Janumet ${ }^{\mathrm{TM}} 50 / 1000$ twice daily if further glucose lowering is desired. For patients taking $850 \mathrm{mg}$ of metformin twice daily, the manufacturer recommends starting Janumet ${ }^{\mathrm{TM}}$ at 50/1000 mg twice daily. ${ }^{19}$ Due to the effects of metformin on the gastrointestinal system, the combination should be given with meals. Special consideration must be given to patients with renal insufficiency. The package insert of metformin suggests patients with renal disease or insufficiency as evidenced by a serum creatinine of $>1.5 \mathrm{mg} / \mathrm{dL}$ in males or $1.4 \mathrm{mg} / \mathrm{dL}$ in females should not take metformin. The package insert of Janumet ${ }^{\mathrm{TM}}$ lists the same contraindications. In addition, patients undergoing radiologic studies involving intravascular administration of iodinated contrast materials should temporarily discontinue Janumet ${ }^{\mathrm{TM}} \cdot{ }^{19}$
Sitagliptin has not been approved in combination with other antidiabetic agents. However, in clinical trials sitagliptin has been given in combination with glimepiride, glipizide and pioglitazone. If initiating sitagliptin in patients on sulfonylureas, the dose of the sulfonylurea may need to be reduced to avoid the risk of hypoglycemia. ${ }^{16}$ Sitagliptin has not been studied with concomitant insulin therapy.

\section{Place in therapy}

Lifestyle modifications are the cornerstone of treatment for T2DM and should be implemented early in the course of the disease. Weight loss may significantly improve glucose levels; unfortunately this cost effective approach is met with limited long-term success. ${ }^{22}$ Consequently, the majority of patients with type 2 diabetes require the addition of pharmacotherapy (Table 2).

The currently available treatment options target at least three core defects in diabetes by improving insulin sensitivity, improving insulin resistance, or impeding secretion of glucagon. Despite the large arsenal of drug therapies, choosing an appropriate treatment poses a challenge for the health care provider. This challenge is compounded when the initial therapy fails and a choice of adjunctive treatment must be chosen. The American Diabetes Association (ADA) and The European Association for the Study of Diabetes have developed an evidence based algorithm to guide the practitioner in initial as well as adjunctive treatment. ${ }^{24}$ In combination with lifestyle modifications, metformin should be implemented first line. In addition to its glucose lowering ability, metformin is recommended for its lack of weight gain, high patient tolerability, and cost. To ensure patient compliance, metformin should be titrated slowly and increased to maximum doses over one to two months.

Patients unable to attain glycemic control (A1c < 7\%) with maximum doses of metformin should receive an additional agent. Step 2 of the algorithm advocates adding either insulin or a sulfonylurea. ${ }^{24}$ The A1c will determine which agent to add. If the A1c level is greater than $8.5 \%$, consideration is given to the addition of insulin. Initiation of insulin can either be intermediate acting insulin at bedtime or longer acting insulin given at either bedtime or in the morning. Conversely, adding a sulfonylurea to metformin in patients with a lesser degree of hyperglycemia (ie, A1c $<8.5 \%$ ) is recommended. If these choices do not produce target glycemic levels, the final step is to intensify insulin treatment or begin insulin if not done in the previous step.

In certain populations, the algorithm recognizes other alternatives. Particularly, if hypoglycemia becomes 
Table 2 Comparison of approved antidiabetic medications in the United States ${ }^{7,16,23}$

\begin{tabular}{|c|c|c|c|c|}
\hline Medication & Class & Dosage form & Alc reduction (\%) & Adverse effects \\
\hline metformin & Biguanides & Oral & 1.5 & $\begin{array}{l}\text { Gastrointestinal effects, rare } \\
\text { lactic acidosis }^{a}\end{array}$ \\
\hline $\begin{array}{l}\text { glipizide, glimepiride, } \\
\text { glyburide }\end{array}$ & Sulfonylureas & Oral & 1.5 & Hypoglycemia, weight gain \\
\hline rosiglitazone, pioglitazone & Thiazolidinediones & Oral & $0.8-1.0$ & $\begin{array}{l}\text { Weight gain, exacerbation of } \\
\text { heart failure }\end{array}$ \\
\hline nateglinide, repaglinide & Meglitinides & Oral & $\mathrm{I}-\mathrm{I} .5$ & Hypoglycemia, weight gain \\
\hline acarbose, miglitol & $\alpha$-glucosidase inhibitors & Oral & $0.5-0.8$ & Gastrointestinal effects \\
\hline Various trade names & Insulin & Parenteral & $\geq 2.5$ & Hypoglycemia, weight gain \\
\hline pramlintide & Amylinomimetics & Parenteral & 0.6 & $\begin{array}{l}\text { Gastrointestinal effects, } \\
\text { hypoglycemia }^{b}\end{array}$ \\
\hline exenatide & GLP-I analog & Parenteral & $0.5-1.0$ & Gastrointestinal effects \\
\hline sitagliptin & DPP-IV inhibitors & Oral & $0.5-0.9$ & Nasopharyngitis, URI, headache \\
\hline
\end{tabular}

alncidence in 0.03 cases per 1000 patient years.

'Black-box warning for severe insulin-induced hypoglycemia if administered within 3 hours of insulin.

Abbreviations: A Ic, glycosylated hemoglobin; DPP-IV, dipeptidyl peptidase IV; GLP, glucagon-like peptide; URI, upper respiratory tract infection.

an issue, addition of pioglitazone or exenatide may be considered. Rosiglitazone is no longer recognized in the consensus algorithm. Several meta-analyses have suggested a relative increase in the risk of myocardial infarction. ${ }^{25-27}$ The panel decided unanimously to remove rosiglitazone while recognizing that the information currently available is not conclusive regarding the cardiovascular risk associated with rosiglitazone. Other agents are mentioned, but their greater expense and lack of evidence limits their use to special populations. This includes the class of DPP-IV inhibitors.

Sitagliptin was the first DPP-IV approved in 2006. Unlike other newer agents, pramlintide and exenatide, sitagliptin offers the advantage of oral administration. Clinical trials indicate sitagliptin is effective in both monotherapy and combination therapy. It has been studied extensively with metformin. This combination does not cause increased side effects or alter the pharmacokinetics of either agent.

Sitagliptin does not cause hypoglycemia or weight gain which has plagued other classes of antihyperglycemics. The A1c lowering of the DPP-IV inhibitor class is approximately $0.6 \%$ to $0.9 \%$, which is less than the first tier agents recommended by the ADA. Several factors must be considered when deciding upon adjunctive therapy including side effects, route of administration, cost, and patient preference. Clinicians should also assess the risks versus benefits when selecting optimal treatment. DPP-IV inhibitors may be most appropriate for patients experiencing hypoglycemia or in patients already on dual oral therapy (sulfonylurea and metformin) with an A1c close to goal. Although sitagliptin is not associated with greater glucose control compared with conventional therapy, it is effective, well tolerated, and provides sustainable reductions in A1c.

\section{Conclusion}

Type 2 diabetes mellitus is a chronic, progressive disease often requiring two or more medications to obtain optimal glucose control. With the discovery of the incretin effect came the emergence of a new class of drugs, the DPP-IV inhibitors. The exact role of sitagliptin, the prototype DPP-IV inhibitor, remains to be explored. Currently, the ADA recommends metformin as the initial agent of choice, followed by sulfonylureas and insulin as preferred adjunctive therapy. Patients experiencing hypoglycemia on conventional therapy, or remaining above the desired A1c goal, may be candidates for sitagliptin. Evidence suggests that combining metformin and sitagliptin provides a positive effect on body weight and A1c with the convenience of oral administration. It is also proven to be safe, efficacious and well tolerated. Although the combination of sitagliptin and metformin appears effective, the use of this combination may be restricted by its relatively high cost and lack of long term safety data. Also, information on sitagliptin in combination with other antidiabetic agents is lacking.

\section{Disclosures}

The authors have no conflicts of interest to disclose. 


\section{References}

1. Centers for Disease Control and Prevention. Diabetes. accessed January 18 2006. Available at http://www.cdc.gov/diabetes/pubs/pdf/ndfs_2005.pdf.

2. Weber A. Dipeptidyl peptidase IV inhibitors for the treatment of diabetes. J Med Chem. 2004;47:4135-4141.

3. Dooseop K, Wang L, Beconi M, Eiermann GJ, Fisher MH, He H, et al. (2R)4-oxo-4-[3-(trifluoromethyl)-5,6-dihydro[1,2,4]triazolo[4,3-a]pyrazin7(8H)-yl]-1-(2,4,5-trifluorophenyl)butan-2-amine: a potent, orally active dipeptidyl peptidase IV inhibitor for the treatment of type 2 diabetes. $\mathrm{JMed}$ Chem. 2005;48(1):141-151.

4. Creutzfeldt W. The [pre-] history of the incretin concept. Regul Pept. 2005;128:87-91.

5. McIntosh C, Demuth H, Pospisilik J, Pederson R. Dipeptidyl peptidase IV inhibitors: how do they work as new antidiabetic agents? Regul Pept. 2005;128:159-165.

6. Vilsboll T, Krarup T, Deacon C, Madsbad S, Holst J. Reduced postprandial concentrations of intact biologically active glucagons-like peptide 1 in type 2 diabetic patients. Diabetes. 2001;50:609-613.

7. Langley AK, Suffoletta TJ, Jennings HR. Dipeptidyl peptidase IV inhibitors and the incretin system in type 2 diabetes mellitus. Pharmacotherapy. 2007;27(8):1163-1180.

8. Karasik A, Aschner P, Katzeff H, Davies M, Stein P. Sitagliptin, a dpp-4 inhibitor for the treatment of patients with type 2 diabetes: a review of recent clinical trials. Curr Med Res Opin. 2008;24(2):489-496.

9. Brazg R, Xu L, Man C, et al. Effect of adding sitagliptin, a dipeptidyl peptidase-4 inhibitor, to metformin on 24-h glycemic control and $\beta$-cell function in patients with type 2 diabetes. Diabetes Obes Metab. 2007;9:186-193.

10. Goldstein, Feinglos M, Lunceford J, et al. Effect of initial combination therapy with sitagliptin, a dipeptidyl peptidase-4 inhibitor, and metformin on glycemic control in patients with type 2 diabetes. Diabetes Care. 2007;30(8):1979-1987.

11. Charbonnel, Karasik A, Liu J, et al. Efficacy and safety of the dipeptidyl peptidase-4 inhibitor sitagliptin added to ongoing metformin therapy in patients with type 2 diabetes inadequately controlled with metformin alone. Diabetes Care. 2006;29(12):2638-2643.

12. Karasik A, Wu M, Williams-Herman D, et al. Sitagliptin added to ongoing metformin therapy provides sustained glycemic control over 54 weeks, with a low incidence of hypoglycemia and with weight loss (abstract 0523-P). Diabetes Care. 2005;28:1083-1091.

13. Nauck M, Meininger G, Sheng D, et al. Efficacy and safety of the dipeptidyl peptidase-4 inhibitor, sitagliptin, compared with the sulfonylurea, glipizide, in patients with type 2 diabetes inadequately controlled on metformin alone: a randomized, double-blind, noninferiority trial. Diabetes Obes Metab. 2007;9:194-205.

14. Hermansen K, Kipnes M, Luo E, et al. Efficacy and safety of the dipeptidyl peptidase- 4 inhibitor, sitagliptin, in patients with type 2 diabetes mellitus inadequately controlled on glimepiride alone or on glimepiride and metformin. Diabetes Obes Metab. 2007;9:733-745.
15. Rosenstock J, Brazg R, Andryuk P, et al. Efficacy and safety of the dipeptidyl peptidase-4 inhibitor sitagliptin added to ongoing pioglitazone therapy in patients with type 2 diabetes: a 24-week, multicenter, randomized, double-blind, placebo-controlled, parallel-group study. Clin Ther. 2006;28(10):1556-1568.

16. VanDeKoppel S, Choe HM, Sweet BV. Managed care perspective on three new agents for type 2 diabetes. J Manag Care Pharm. 2008;14(4):363-380.

17. Herman GA, Bergman A, Yi B, Kipnes M, for the sitagliptin study 012 group. Tolerability and pharmacokinetics of metformin and the dipeptidyl peptidase-4 inhibitor sitagliptin when co-administered in patients with type 2 diabetes. Curr Med Res Opin. 2006;22(10): 1939-1947.

18. Florentin M, Liberopoulos EN, Mikhailidis DP, Elisaf MS. Sitagliptin in clinical practice: a new approach in the treatment of type 2 diabetes. Expert Opin Pharmacother. 2008;9(10):1705-1720.

19. Janumet package insert. Whitehouse Station, NJ: Merck and company; 2008. http://www.merck.com/product/usa/pi_circulars/j/janumet/ janumet_pi.pdf.

20. Glucophage (metformin), package insert. Princeton, NJ: BristolMyers Squibb Company, 2008. http://packageinserts.bms.com/pi/ pi_glucophage.pdf.

21. Januvia package insert. Whitehouse Station, NJ: Merck and company; 2008 http://www.merck.com/product/usa/pi_circulars/j/januvia/ januvia_pi.pdf.

22. Nathan DM, Buse JB, Davidson MB, et al. Management of hyperglycemia in Type 2 Diabetes: A consensus algorithm for the initiation and adjustment of therapy. A consensus statement from the American Diabetes Association and the European Association for Study of Diabetes. Diabetes Care. 2006;29(8):1963-1971.

23. Krentz AJ, Bailey CJ. Oral antidiabetic agents current role in type 2 diabetes. Drugs. 2005:65(3):385-411.

24. Nathan DM, Buse JB, Davidson MB, et al. Medical management of hyperglycemia in Type 2 Diabetes: A consensus algorithm for the initiation and adjustment of therapy. A consensus statement from the American Diabetes Association and the European Association for Study of Diabetes. Diabetes Care. 2008;31(12):1-11.

25. Nathan DM, Buse JB, Davidson MB, et al. Management of hyperglycemia in Type 2 Diabetes: A consensus algorithm for the initiation and adjustment of therapy. Update regarding thiazolidinediones: a consensus statement from the American Diabetes Association and the European Association for Study of Diabetes. Diabetes Care. 2008;31(1):173-175.

26. Nissen SE, Wolski K. Effect of rosiglitazone on the risk of myocardial infarction and death from cardiovascular causes. $N$ Engl J Med. 2007;356:1-15.

27. Singh S, Loke YK, Furberg CD. Long-term risk of cardiovascular events with rosiglitazone: a meta-analysis. JAMA. 2007;298(10): 1189-1195.

Diabetes, Metabolic Syndrome and Obesity: Targets and Therapy

Dovepress

\section{Publish your work in this journal}

Diabetes, Metabolic Syndrome and Obesity: Targets and Therapy is an international, peer-reviewed open-access journal committed to the rapid publication of the latest laboratory and clinical findings in the fields of diabetes, metabolic syndrome and obesity research. Original research, review, case reports, hypothesis formation, expert opinion and commentaries are all considered for publication. The manuscript management system is completely online and includes a very quick and fair peer-review system, which is all easy to use. Visit http://www.dovepress.com/testimonials.php to read real quotes from published authors. 